\title{
Components of Foods Inhibit a Drug Exporter, Human Multidrug and Toxin Extrusion Transporter 1
}

\author{
Tatsuya Kawasaki, ${ }^{a}$ Hideyuki Ito, ${ }^{b}$ and Hiroshi Omote ${ }^{*, a}$ \\ ${ }^{a}$ Department of Membrane Biochemistry, Okayama University Graduate School of Medicine, Dentistry and \\ Pharmaceutical Sciences; and ${ }^{b}$ Department of Natural Product Chemistry, Okayama University Graduate School of \\ Medicine, Dentistry and Pharmaceutical Sciences; Okayama 700-8530, Japan.
}

Received October 17, 2013; accepted November 4, 2013

\begin{abstract}
Human multidrug and toxic compounds extrusion transporter 1 (hMATE1/SLC47A1) is a $\mathrm{H}^{+}$-coupled organic cation exporter responsible for the final step of excretion of various xenobiotics at the kidney and liver. In this study, effects of dietary constituents on hMATE1 mediated drug transport were examined to evaluate possible food-drug interactions. Bergamottin inhibited hMATE1 mediated tetraethyl ammonium transport activity, with a $K_{\mathrm{i}}$ of $98.7 \mu \mathrm{M}$. Coumarins, flavonols, and catechin inhibited hMATE1 activity. Among 23 compounds tested, isorhamnetin was the strongest inhibitor of hMATE1 with the $K_{\mathrm{i}}$ of $0.32 \mu \mathrm{M}$ in a competitive manner. Since isorhamnetin is abundant in Ginkgo biloba that is widely used for herbal supplements, the findings suggest the potential hMATE1 related food-drug interactions.
\end{abstract}

Key words multidrug and toxic compounds extrusion; food-drug interaction; isorhamnetin; multidrug and toxin extrusion (MATE); Ginkgo biloba

Food-drug interactions are increasing in interest since they have unexpected effects in drug therapy. It has been shown that the concomitant intake of grapefruit juice affects the disposition of various drugs such as calcium channel blockers including nifedipine, nitrendipine and verapamil. ${ }^{1-4)}$ Bergamottin is known to be an active compound of grapefruit juice that affects the pharmacokinetics of various drugs through inhibition of CYP3A4. ${ }^{4-13)}$ Recent progress of drug transporter studies with bergamottin and flavonoids revealed that multidrug transporters including P-glycoprotein and organic anion transporting peptide (OATP) also play important roles in food-drug interactions. ${ }^{14-16)}$

Multidrug and toxin extrusion 1 (MATE1; SLC47A1) is an electroneutral $\mathrm{H}^{+}$/organic cation antiporter that functions as an efflux transporter of many organic compounds into the bile and urine. ${ }^{17)}$ Detailed kinetic studies indicated that hMATE1 recognizes various drugs such as cimetidine, quinidine, verapamil and metformin. ${ }^{17,18)}$ Since MATE1 is responsible for the excretion of toxic metabolites and xenobiotics, inhibition of this transporter affect the pharmacokinetics of cationic drugs. In fact, a single-nucleotide polymorphism of hMATE1 is associated with altered pharmacokinetics of metformin. ${ }^{19)}$ Furthermore, a MATE specific inhibitor, pyrimethamine, significantly reduced the renal clearance of metformin. ${ }^{20)}$ Chemical compounds of exogenous origins affecting hMATE1 may increase the blood concentrations and clearance rates of prescribed drugs. Thus, MATE1 could be an important target for food-drug and drug-drug interactions. Although various compounds are known to inhibit organic cation export in renal brush border membranes and bile canaliculi, detailed studies of food-drug interactions are still in progress. In particular, little is known about xenobiotics affecting the activity of hMATE1. In this study, we focused on dietary constituents including bergamottin and flavonoids since these compounds affect pharmacokinetics of various drugs, and evaluated the inhibitory effects on hMATE1-mediated tetraethylammonium (TEA) transport activity.

The authors declare no conflict of interest.

\section{MATERIALS AND METHODS}

Chemicals $\left[1-{ }^{14} \mathrm{C}\right]$-TEA $(118.4 \mathrm{GBq} / \mathrm{mmol})$ was purchased from PerkinElmer Life Sciences Inc. (Waltham, U.S.A.). Coumarins, flavonols and catechins were purchased from Extrasynthese (Lyon, France). Dulbecco's modified Eagle's medium (DMEM) and fetal bovine serum were obtained from Invitrogen. All other reagents were of analitical grade and commercially obtained. The chemical structures of the tested compounds are shown in Fig. 1.

Cell Culture HEK293 cells were maintained at $37^{\circ} \mathrm{C}$ under a humidified atmosphere containing $5 \% \mathrm{CO}_{2}$ in DMEM supplemented with $55 \mathrm{mg} / \mathrm{L}$ sodium pyruvate, $10 \%$ heat-inactivated fetal bovine serum, $10^{5}$ units/L penicillin, $100 \mathrm{mg} / \mathrm{L}$ streptomycin, and $250 \mu \mathrm{g} / \mathrm{L}$ fungizone. The cells were routinely subcultured by $0.04 \%$ trypsinization using trypsin- $-0.02 \%$ ethylenediaminetetraacetic acid (EDTA) solution.

Establishment of Stable Cell Lines A plasmid carrying the cDNA of hMATE1 was described previously. ${ }^{17)}$ This pcDNA3.1(+)-hMATE1 plasmid was used to transfect HEK293 cells by lipofection using TransIT reagent (Mirus). Forty-eight hours after transfection, $800 \mathrm{mg} / \mathrm{L}$ geneticin (G418) was added to the medium. Two weeks after the addition of geneticin, a stable clone was isolated by Western blotting using anti hMATE1 antibodies. ${ }^{17)}$

Expression Test Membranes of HEK293 cells were isolated as follows. Cultured cells $\left(2.0 \times 10^{7}\right.$ cells $)$ were suspended in ice-cold $20 \mathrm{~mm} 3$-morpholinopropane sulfonic acid (MOPS)Tris, $\mathrm{pH}$ 7.0, containing $0.3 \mathrm{~m}$ sucrose, $5 \mathrm{~mm}$ EDTA, and protease inhibitors (pepstatin $A$ and leupeptin at $5 \mathrm{mg} / \mathrm{L}$ each), homogenized, and then centrifuged at $800 \times \boldsymbol{g}$ for $8 \mathrm{~min}$ at $4^{\circ} \mathrm{C}$. The postnuclear supernatant was centrifuged at $100000 \times \boldsymbol{g}$ for $1 \mathrm{~h}$ at $4^{\circ} \mathrm{C}$. The pellet was suspended in the same buffer, solubilized with dissociation buffer containing sodium dodecyl sulfate (SDS), and then used for polyacrylamide gel electrophoresis in the presence of SDS. Polyacrylamide gel electrophoresis and Western blotting were performed as described previously. ${ }^{21)}$ Protein concentrations were determined using the Bio-Rad protein assay using bovine serum albumin 


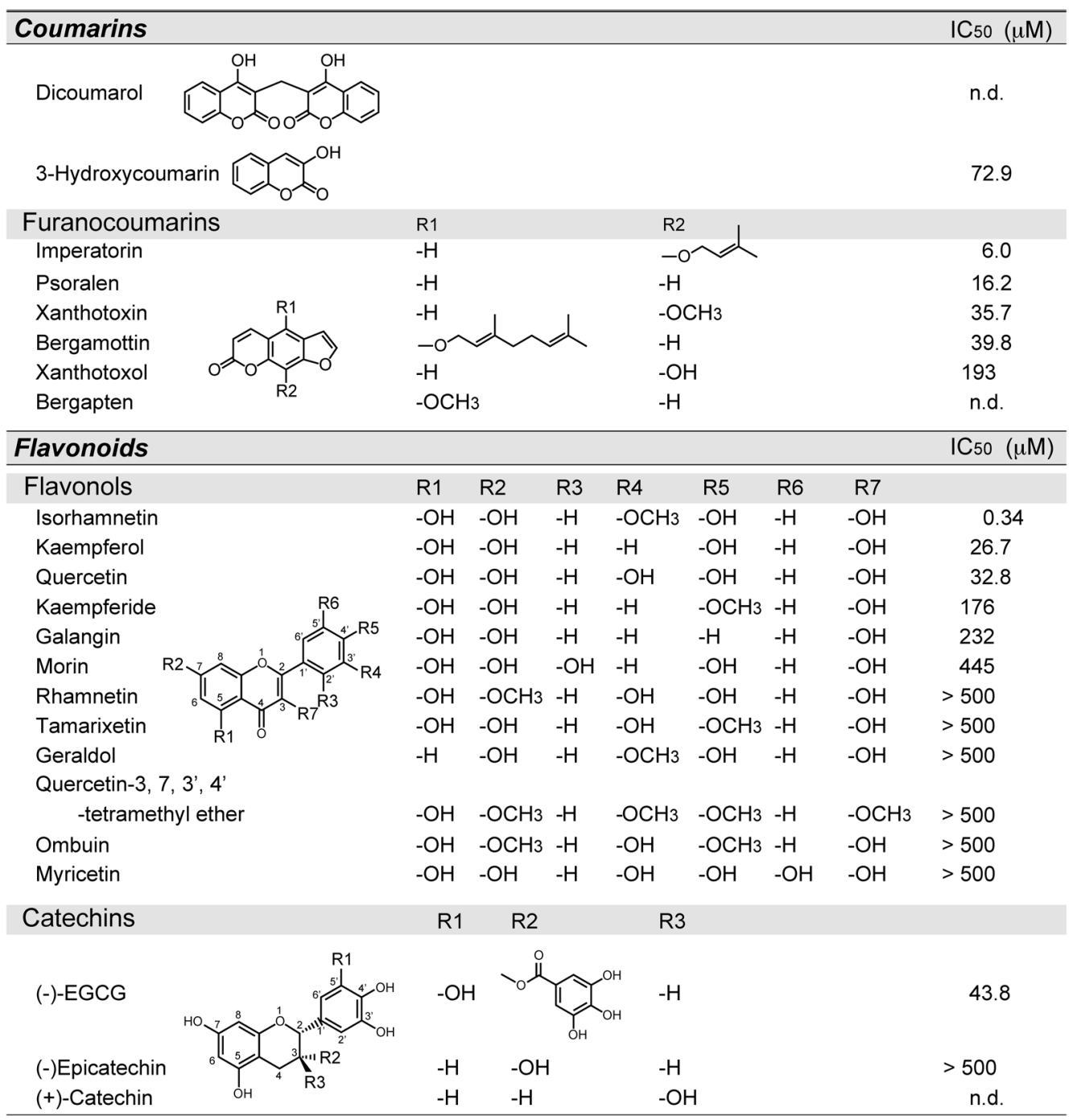

Fig. 1. Chemical Structures and $\mathrm{IC}_{50}$ Values of Tested Compounds

The structures of the tested compounds are shown. $\mathrm{IC}_{50}$ values were obtained through triplicated experiments as described in Materials and Methods. n.d., not determined.

as a standard.

Transport Assay TEA uptake was measured with mock and stably hMATE1 expressing HEK293 cells grown on BD polystyrene-treated 24 -well plates. HEK293 cells $\left(1.0 \times 10^{5}\right.$ cells/well) were grown on 24-well plates containing DMEM supplemented with $10 \%$ fetal calf serum, $100 \mu \mathrm{g} / \mathrm{mL}$ penicillin, and $0.25 \mu \mathrm{g} / \mathrm{mL}$ streptomycin at $37^{\circ} \mathrm{C}$ under $5 \% \mathrm{CO}_{2}$. Forty-eight hours later, the cells were washed twice with $800 \mu \mathrm{L}$ of an assay medium $(125 \mathrm{~mm} \mathrm{NaCl}, 4.8 \mathrm{~mm} \mathrm{KCl}, 5.6 \mathrm{~mm} \mathrm{D}-$ glucose, $1.2 \mathrm{mM} \mathrm{CaCl}_{2}, 1.2 \mathrm{~mm} \mathrm{KH}_{2} \mathrm{PO}_{4}, 1.2 \mathrm{mM} \mathrm{MgSO}_{4}$, and $25 \mathrm{~mm}$ Tricine, $\mathrm{pH} 8.0$ ). Then, the cells were incubated at $37^{\circ} \mathrm{C}$ for $5 \mathrm{~min}$, transport being initiated by adding $\left[{ }^{14} \mathrm{C}\right]-\mathrm{TEA}$ $(0.5 \mathrm{GBq} / \mathrm{mmol})$ to a final concentration of $50 \mu \mathrm{M}$. After $10 \mathrm{~min}$ incubation at $37^{\circ} \mathrm{C}$, the cells were washed twice with $800 \mu \mathrm{L}$ ice-cold assay medium. The cells were lysed with $400 \mu \mathrm{L} 0.5 \mathrm{M}$ $\mathrm{NaOH}$, and the radioactivity was counted with a liquid scintillation counter.

Data Analysis For calculation of $\mathrm{IC}_{50}$ values, the percentage of uptake inhibition was calculated from the results of control experiments in the absence of the tested compounds (100\% uptake). The corresponding $\mathrm{IC}_{50}$ values for the inhibition of hMATE1-mediated $\left[{ }^{14} \mathrm{C}\right]-\mathrm{TEA}$ uptake by the tested compounds were calculated by fitting to a dose-response curve using KaleidaGraph 3.6 (HULINKS) as previously reported. ${ }^{22}$ Fitting curve was given by Eq. 1 and $\mathrm{IC}_{50}$ was obtained from Eq. 2.

$$
\begin{gathered}
f(x)=1 /\left(1+e^{(\alpha-\beta(\log x+\gamma)}\right) \\
\mathrm{IC}_{50}=10^{(\alpha / \beta-\gamma)}
\end{gathered}
$$

All data are presented as means \pm S.E.M., $n=3-9$.

To determine the kinetic type of inhibitions (isorhamnetin and bergamottin), the uptake of $\left[{ }^{14} \mathrm{C}\right]-\mathrm{TEA}$ was determined in the presence of increasing concentrations of the inhibitors. The $K_{\mathrm{i}}$ values were calculated using SigmaPlot 12.3 (HULINKS) by fitting data to Eq. 3.

$$
v=V_{\max } \cdot[\mathrm{S}] /\left\{[\mathrm{S}]+K_{\mathrm{m}}\left(1+[\mathrm{I}] / K_{\mathrm{i}}\right)\right\}
$$

Where $v$ is the TEA transport rate; [I] and [S] are inhibitor and substrate concentrations. 


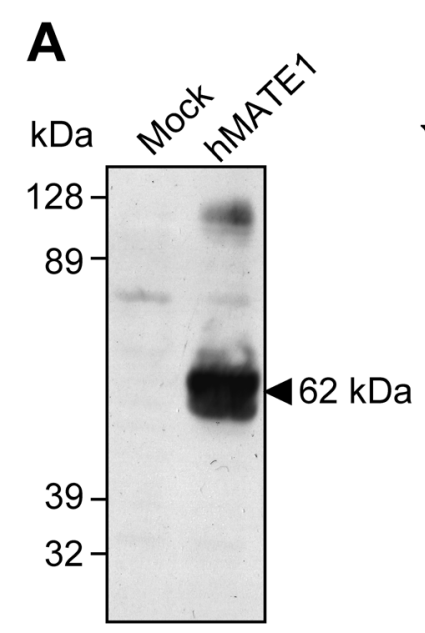

B

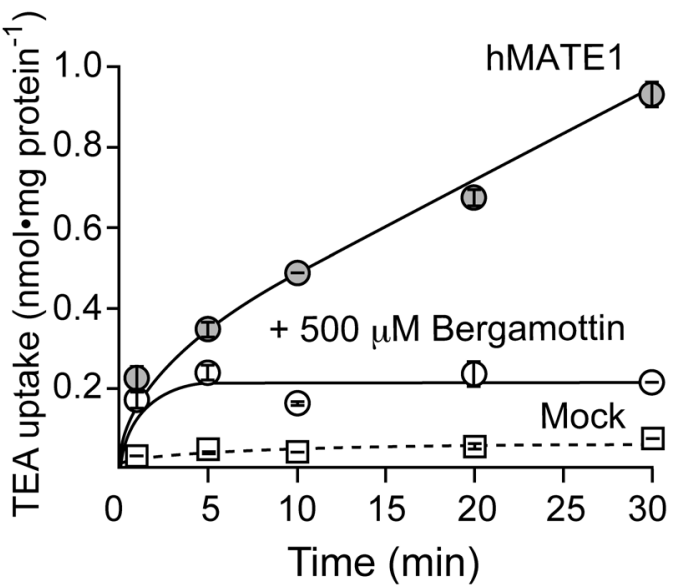

Fig. 2. TEA Uptake by hMATE1 Expressing HEK293 Cells

(A) Western blot analysis with an antibody against hMATE1. Membrane fractions of hMATE1 expressing or mock HEK293 cells were analyzed by Western blotting using anti hMATE1 antibodies. ${ }^{17)}$ Immunoreactive proteins were visualized using an ECL detection kit (Amersham Biosciences). The position of hMATE1 is indicated by an arrowhead. (B) Time course of TEA uptake into HEK293 cells stably expressing hMATE1 and into mock cells. The uptake of $\left[{ }^{14} \mathrm{C}\right]-\mathrm{TEA}(50 \mu \mathrm{M})$ was measured at the indicated time at $37^{\circ} \mathrm{C}$, and $\mathrm{pH} 8.0$ in the presence or absence of bergamottin $(500 \mu \mathrm{M})$. Data are presented as means \pm S.E.M., $n=3$.
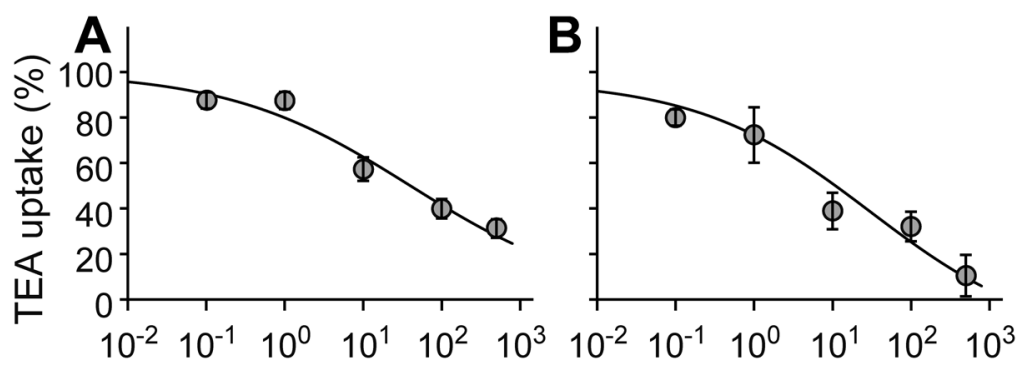

Bergamottin $(\mu \mathrm{M})$

Imperatorin $(\mu \mathrm{M})$
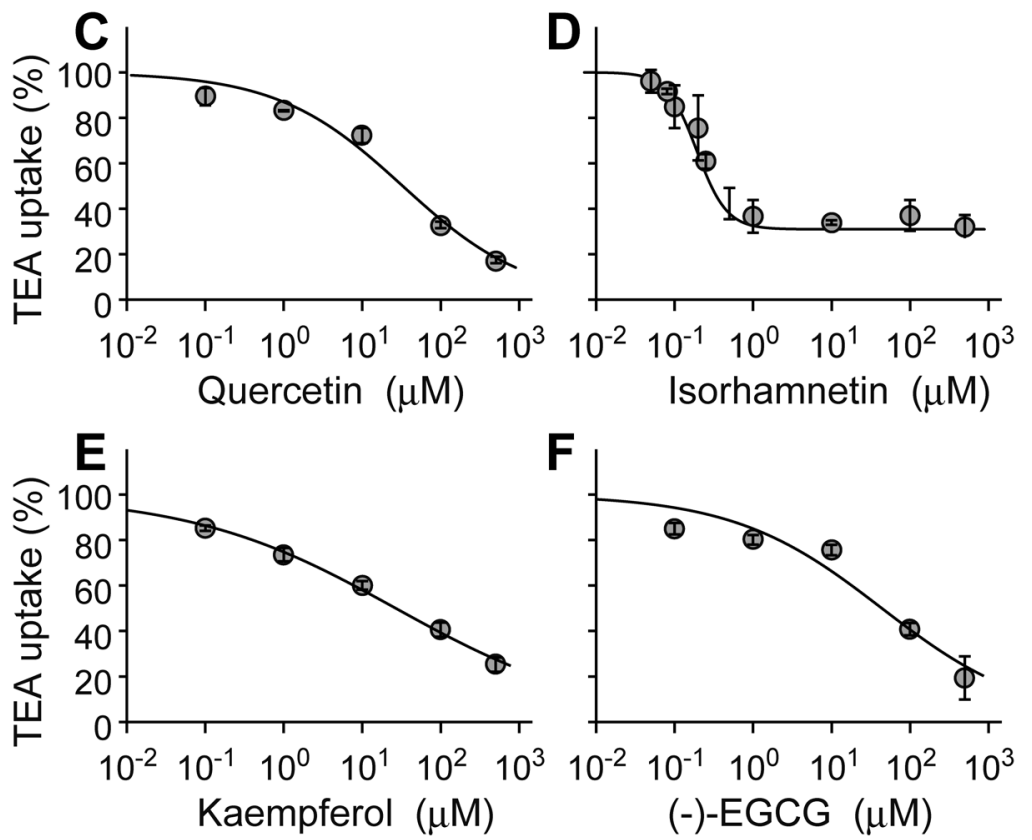

Fig. 3. Inhibition of hMATE1 Mediated TEA Uptake by Various Compounds

The uptake of $\left[{ }^{14} \mathrm{C}\right]$-TEA $(50 \mu \mathrm{M})$ was measured for $5 \mathrm{~min}$ at $37{ }^{\circ} \mathrm{C}$ and $\mathrm{pH} 8.0$ in the presence or absence of the indicated compounds $(0.1-500 \mu \mathrm{M})$. The averaged TEA uptake for the control was $0.10 \pm 0.01\left(\mathrm{nmol} \cdot \mathrm{mg}\right.$ protein $\left.{ }^{-1} \cdot \mathrm{min}^{-1}\right)$. Inhibitions by bergamottin (A), imperatorin (B), quercetin (C), isorhamnetin (D), kaempferol (E) and $(-)$-EGCG (F) are shown. Data are expressed as percentages of the control. All data are presented as means \pm S.E.M., $n=3-9$. 


\section{RESULTS}

Bergamottin Is a Natural hMATE1 Inhibitor To examine the effects of dietary constituents on hMATE1 activity, a stable hMATE1 expression line was established by geneticin screening. The expression of hMATE1 in HEK293 cells derived from an isolated colony was examined by Western blot analysis. An immunoreactive band at $62 \mathrm{kDa}$ which corresponded to the molecular weight of hMATE1, was observed for the membranes of HEK293 cells expressing hMATE1 (Fig. 2A). However mock cells did not show immunoreactivity except for minor nonspecific band at $c a$. $80 \mathrm{kDa}$. Immunoreactivity at $128 \mathrm{kDa}$ may correspond to hMATE1 dimer. hMATE1 activity was measured as $\left[{ }^{14} \mathrm{C}\right]$-TEA $(50 \mu \mathrm{M})$ uptake by HEK293 cells. When cells were incubated at an alkaline $\mathrm{pH}$, which generates a downhill $\mathrm{H}^{+}$gradient across the plasma membrane, hMATE1 expressing HEK293 cells took up TEA in a time dependent manner up to $30 \mathrm{~min}$ (Fig. 2B). On the other hand, mock cells did not show significant TEA uptake. These results indicate that the established HEK293 cell line is useful for measuring hMATE1 activity. Initially we tested the effect of bergamottin, which is a major ingredient of grapefruit juice, regarding food-drug interactions. When $500 \mu \mathrm{m}$ bergamottin was included in the medium, TEA uptake was greatly inhibited, suggesting hMATE1 is sensitive to this compound (Fig. 2B).

Inhibitory Effects of Natural Compounds on hMATE1 Transport Activity Since bergamottin is a furanocoumarin, we examined the effects of various coumarins on hMATE1mediated TEA uptake (Figs. 1, 3). Most coumarins caused dose-dependent inhibition of TEA uptake, the exceptions being dicoumarol and bergapten. These two coumarins were insoluble at higher than $10 \mu \mathrm{m}$ and thus inhibition could not be measured at higher concentrations. Bergamottin, psoralen and xanthotoxin inhibited TEA uptake to similar extents. Among the tested coumarins, imperatorin caused the strongest inhibition, the apparent $\mathrm{IC}_{50}$ being $6 \mu \mathrm{M}$ (Figs. 1, 3B).

We also tested 12 flavonols and 3 catechins. As shown in Figs. 1 and 3, isorhamnetin showed strong inhibition of TEA uptake, whereas myricetin, ombuin and quercetin tetramethylether at up to $100 \mu \mathrm{M}$ failed to inhibit TEA uptake (Figs. 1,
3). Other flavonols i.e., kaempferol, quercetin, kaempferide, galangin and morin, caused moderate inhibition (Figs. 1, 3). For catechins, TEA uptake was moderately inhibited by epigallocatechin gallate (EGCG) (Figs. 1, 3F). On the other hand, catechin did not inhibit TEA uptake at the tested concentrations.

The apparent $\mathrm{IC}_{50}$ values for these compounds are summarized in Fig. 1. Among the tested compounds, isorhamnetin was the most potent inhibitor of hMATE1 although it did not show complete inhibition even at high concentrations (Fig. 3D).

Kinetic Analysis of the hMATE1 Inhibition by Bergamottin and Isorhamnetin In order to elucidate the mechanism underlying the hMATE1 inhibition by bergamottin and isorhamnetin, the inhibitory effects of these compounds were measured with various concentrations of TEA and inhibitors (Fig. 4). Clearly, both bergamottin and isorhamnetin caused competitive type inhibition with $K_{\mathrm{i}}$ values of 98.7 and $0.32 \mu \mathrm{M}$, respectively. This suggests these compounds share the same binding site with TEA.

\section{DISCUSSION}

MATE1 is a cationic drug exporter located in the apical membranes of renal tubular cells and hepatocytes. ${ }^{17)}$ Recent pharmacokinetic studies revealed that pyrimethamine is a specific inhibitor of MATE1, the $K_{\mathrm{i}}$ being $c a .90 \mathrm{~nm}^{20,23)}$ Sugiyama and co-workers used pyrimethamine as a tool to determine MATE1 dependent drug efflux and showed that MATE1 is responsible for metformin efflux in human and mouse. ${ }^{20,23)}$ Interestingly, they found pyrimethamine treatment increased the hepatic or plasma metformin concentrations, and caused greater gluconeogenesis inhibition, indicating a metforminpyrimethamine interaction through MATE1. ${ }^{20,23)}$ These studies indicated the importance of MATE1 in the efflux of cationic drugs and in the drug-drug interactions.

In the present study, we showed the inhibition of hMATE1 by bergamottin. Bergamottin is well known as an ingredient of grapefruit juice and causes food-drug interactions by interfering with CYP activity. ${ }^{1-4)}$ Plasma bergamottin concentration after grapefruit juice intake is reported as $2-10 \mathrm{~nm}$, far

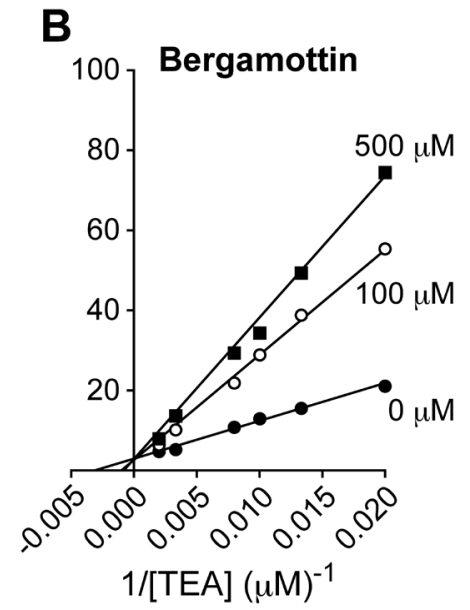

Fig. 4. Competitive Inhibition of TEA Uptake by Isorhamnetin and Bergamottin

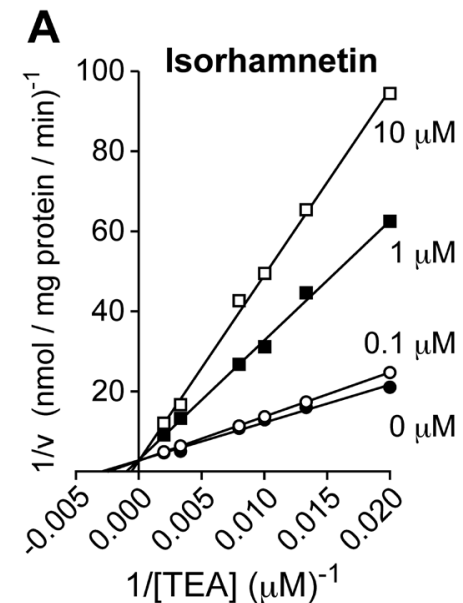

(A) Inhibition by isorhamnetin. TEA uptake by HEK 293 cells expressing hMATE1 was measured with various concentrations of isorhamnetin $(0,0.1,1$ and $10 \mu \mathrm{M})$ or TEA $(50-500 \mu \mathrm{M})$. (B) Inhibition by bergamottin $(0,100$ and $500 \mu \mathrm{M})$. Data are presented as means \pm S.E.M., $n=4$. 
lower than the observed $K_{\mathrm{i}}$ value. ${ }^{3)}$ Our study suggests bergamottin in food may not interfere with the pharmacokinetics of cationic drugs through hMATE1.

Inhibition of hMATE1 by bergamottin also suggests the possibility that hMATE1 is inhibited by other compounds in food. As expected, many flavonols and coumarines inhibited hMATE1. Among 23 compounds tested, isorhamnetin was the strongest inhibitor of hMATE1. Isorhamnetin is the major flavonoid in Ginkgo biloba L. ${ }^{24)}$ It is also well known as a metabolite of quercetin. ${ }^{25,26)}$ de Pascual-Teresa and co-workers reported that the plasma isorhamnetin concentration after oral administration of quercetin-rich food is $c a .0 .36 \mu \mathrm{M}^{27)}$ This value is comparable to the $\mathrm{IC}_{50}$ and $K_{\mathrm{i}}$ values for isorahamnetin, indicating special caution is required when taking G. biloba supplements and/or quercetin-rich foods. G. biloba is used to treat mild cognitive impairment and dementia although it effect is still controversial. ${ }^{28,29)}$ Since G. biloba leaves are among the most widely used herbal remedies in the United States, further investigation of $G$. biloba and its interaction with metabolic targets are required. ${ }^{28)}$

Although isorhamnetin and bergamottin have different structures, they inhibited hMATE1 mediated TEA uptake in a typical competitive manner. This indicates these two compounds and TEA share the same binding site.

The inhibitory effects of the tested compounds were highly dependent on the positions of the hydroxyl and methoxy groups on the flavonol. For instance, isorhamnetin and geraldol are only different in the 5-hydroxyl group. However, hMATE1 is not sensitive to geraldol, indicating the importance of the 5-hydroxyl group for inhibition. Isorhamnetin, kaempferol and quercetin have the same structure except for the functional group at the $3^{\prime}$ position. Isorhamnetin has a methoxy group at this position, and shows a $c a .100$ fold lower $\mathrm{IC}_{50}$ than kaempferol and quercetin. When quercetin and rhamnetin are compared, it can be seen they have the same structure except for the functional group at position 7. Quercetin has a hydroxyl group at this position, whereas rhamnetin has a methoxy group and this group causes more than 10 fold weaker inhibition. Also, the importance of a hydroxyl group at the $4^{\prime}$ position was indicated by quercetin and tamarixetin inhibition. These results indicate that hydroxyl groups at positions 5, 7 and 4', and a methoxy group at position $3^{\prime}$ are important for inhibition of hMATE1. Interestingly, isorhamnetin has hydroxyl groups at positions 3, 5, 7 and 4', and a methoxy group at position $3^{\prime}$, and thus fulfills this inhibition constraint.

\section{CONCLUSION}

In conclusion, some coumarins, EGCG, and flavonoids especially for isorhamnetin inhibited hMATE1. These compounds may affect pharmacokinetics through inhibition of drug excretion. Although further in vivo and clinical studies are necessary, our findings point out the hMATE1 related risk of food-drug interactions.

Acknowledgments This study was supported in part by Grants-in-Aid for scientific research from the Ministry of Education, Culture, Sports, Science and Technology of Japan and the Smoking Research Foundation to H.I. and H.O. We thank Dr. Y. Moriyama for his help and discussion.

\section{REFERENCES}

1) Dresser GK, Bailey DG, Carruthers SG. Grapefruit juice-felodipine interaction in the elderly. Clin. Pharmacol. Ther., 68, 28-34 (2000).

2) Takanaga H, Ohnishi A, Murakami H, Matsuo H, Higuchi S, Urae A, Irie S, Furuie H, Matsukuma K, Kimura M, Kawano K, Orii Y, Tanaka T, Sawada Y. Relationship between time after intake of grapefruit juice and the effect on pharmacokinetics and pharmacodynamics of nisoldipine in healthy subjects. Clin. Pharmacol. Ther. 67, 201-214 (2000).

3) Goosen TC, Cillié D, Bailey DG, Yu C, He K, Hollenberg PF, Woster PM, Cohen L, Williams JA, Rheeders M, Dijkstra HP. Bergamottin contribution to the grapefruit juice-felodipine interaction and disposition in humans. Clin. Pharmacol. Ther., 76, 607-617 (2004).

4) Ameer B, Weintraub RA. Drug interactions with grapefruit juice. Clin. Pharmacokinet., 33, 103-121 (1997).

5) Guo LQ, Yamazoe Y. Inhibition of cytochrome P450 by furanocoumarins in grapefruit juice and herbal medicines. Acta Pharmacol. Sin., 25, 129-136 (2004).

6) Bailey DG, Dresser GK. Interactions between grapefruit juice and cardiovascular drugs. Am. J. Cardiovasc. Drugs, 4, 281-297 (2004).

7) Guo LQ, Taniguchi M, Xiao YQ, Baba K, Ohta T, Yamazoe Y. Inhibitory effect of natural furanocoumarins on human microsomal cytochrome P450 3A activity. Jpn. J. Pharmacol., 82, 122-129 (2000).

8) Malhotra S, Bailey DG, Paine MF, Watkins PB. Seville orange juice-felodipine interaction: comparison with dilute grapefruit juice and involvement of furocoumarins. Clin. Pharmacol. Ther., 69, 14-23 (2001).

9) Mohri K, Uesawa Y. Effects of furanocoumarin derivatives in grapefruit juice on nifedipine pharmacokinetics in rats. Pharm. Res., 18, 177-182 (2001).

10) Bailey DG, Dresser GK. Interactions between grapefruit juice and cardiovascular drugs. Am. J. Cardiovasc. Drugs, 4, 281-297 (2004).

11) Kakar SM, Paine MF, Stewart PW, Watkins PB. 6'7'-Dihydroxybergamottin contributes to the grapefruit juice effect. Clin. Pharmacol. Ther., 75, 569-579 (2004).

12) Paine MF, Criss AB, Watkins PB. Two major grapefruit juice components differ in time to onset of intestinal CYP3A4 inhibition. $J$. Pharmacol. Exp. Ther., 312, 1151-1160 (2005).

13) Kimura $\mathrm{Y}$, Ito $\mathrm{H}$, Ohnishi $\mathrm{R}$, Hatano $\mathrm{T}$. Inhibitory effects of polyphenols on human cytochrome P450 3A4 and 2C9 activity. Food Chem. Toxicol., 48, 429-435 (2010).

14) Shirasaka Y, Shichiri M, Mori T, Nakanishi T, Tamai I. Major active components in grapefruit, orange, and apple juices responsible for OATP2B1-mediated drug interactions. J. Pharm. Sci., 102, 3418-3426 (2013)

15) Dolton MJ, Roufogalis BD, McLachlan AJ. Fruit juices as perpetrators of drug interactions: the role of organic anion-transporting polypeptides. Clin. Pharmacol. Ther., 92, 622-630 (2012).

16) Bansal T, Jaggi M, Khar RK, Talegaonkar S. Emerging significance of flavonoids as P-glycoprotein inhibitors in cancer chemotherapy. J. Pharm. Pharm. Sci., 12, 46-78 (2009).

17) Otsuka M, Matsumoto T, Morimoto R, Arioka S, Omote H, Moriyama Y. A human transporter protein that mediates the final excretion step for toxic organic cations. Proc. Natl. Acad. Sci. U.S.A., 102, 17923-17928 (2005).

18) Tanihara Y, Masuda S, Sato T, Katsura T, Ogawa O, Inui K. Substrate specificity of MATE1 and MATE2-K, human multidrug and toxin extrusions $/ \mathrm{H}^{+}$-organic cation antiporters. Biochem. Pharmacol., 74, 359-371 (2007).

19) Becker ML, Visser LE, van Schaik RH, Hofman A, Uitterlinden $\mathrm{AG}$, Stricker BH. Genetic variation in the multidrug and toxin extrusion 1 transporter protein influences the glucose-lowering effect of metformin in patients with diabetes: a preliminary study. Diabe- 
tes, 58, 745-749 (2009).

20) Kusuhara $H$, Ito $S$, Kumagai $Y$, Jiang $M$, Shiroshita $T$, Moriyama $Y$, Inoue K, Yuasa H, Sugiyama Y. Effects of a MATE protein inhibitor, pyrimethamine, on the renal elimination of metformin at oral microdose and at therapeutic dose in healthy subjects. Clin. Pharmacol. Ther., 89, 837-844 (2011).

21) Morimoto R, Hayashi M, Yatsushiro S, Otsuka M, Yamamoto A, Moriyama Y. Co-expression of vesicular glutamate transporters (VGLUT1 and VGLUT2) and their association with synaptic-like microvesicles in rat pinealocytes. J. Neurochem., 84, 382-391 (2003).

22) Lyles RH, Poindexter C, Evans A, Brown M, Cooper CR. Nonlinear model-based estimates of $\mathrm{IC}_{50}$ for studies involving continuous therapeutic dose-response data. Contemp. Clin. Trials, 29, 878-886 (2008).

23) Ito $\mathrm{S}$, Kusuhara $\mathrm{H}$, Kuroiwa $\mathrm{Y}, \mathrm{Wu} \mathrm{C}$, Moriyama $\mathrm{Y}$, Inoue $\mathrm{K}$, Kondo T, Yuasa H, Nakayama H, Horita S, Sugiyama Y. Potent and specific inhibition of mMate1-mediated efflux of type I organic cations in the liver and kidney by pyrimethamine. J. Pharmacol. Exp.
Ther., 333, 341-350 (2010).

24) Oh SM, Chung KH. Estrogenic activities of Ginkgo biloba extracts. Life Sci., 74, 1325-1335 (2004).

25) Gugler R, Leschik M, Dengler HJ. Disposition of quercetin in man after single oral and intravenous doses. Eur. J. Clin. Pharmacol., 9 , 229-234 (1975)

26) Bieger J, Cermak R, Blank R, de Boer VC, Hollman PC, Kamphues $\mathrm{J}$, Wolffram S. Tissue distribution of quercetin in pigs after longterm dietary supplementation. J. Nutr., 138, 1417-1420 (2008).

27) de Pascual-Teresa S, Johnston KL, DuPont MS, O’Leary KA, Needs PW, Morgan LM, Clifford MN, Bao Y, Williamson G. Quercetin metabolites downregulate cyclooxygenase-2 transcription in human lymphocytes ex vivo but not in vivo. J. Nutr., 134, 552-557 (2004).

28) Hermann R, von Richter O. Clinical evidence of herbal drugs as perpetrators of pharmacokinetic drug interactions. Planta Med., 78, 1458-1477 (2012).

29) Weinmann S, Roll S, Schwarzbach C, Vauth C, Willich SN. Effects of Ginkgo biloba in dementia: systematic review and meta-analysis. BMC Geriatr., 10, 14 (2010). 